Review Article

\title{
Prevalence and diagnostic features of osteoarthrosis of the temporomandibular joint: a review
}

\author{
Mohan Bansal* \\ Gujarat Adani Institute of Medical Sciences, Bhuj, Gujarat, India \\ Received: 01 January 2016 \\ Accepted: 26 February 2016 \\ *Correspondence: \\ Dr. Mohan Bansal, \\ E-mail: mohanbansal@yahoo.com \\ Copyright: (c) the author(s), publisher and licensee Medip Academy. This is an open-access article distributed under \\ the terms of the Creative Commons Attribution Non-Commercial License, which permits unrestricted non-commercial \\ use, distribution, and reproduction in any medium, provided the original work is properly cited.
}

\begin{abstract}
Temporomandibular disorders (TMD) consist of not only the internal derangement of Temporomandibular joint (TMJ) but also areas extrinsic to TMJ. Osteoarthritis is a common degenerative joint disease that manifests as a chronic debilitating disease and occurs due to degradation and loss of articular cartilage. There occur changes in the subchondral bone and other soft tissues. Osteoarthritis is not uncommon in the Temporomandibular joints (TMJs). The etiopathogenesis of osteoarthritis is associated with multiple risk factors. The disease progresses slowly and passes through different phases with periods of remission and ultimately results in the burnout phase. It needs a good understanding of the diagnostic algorithm and that facilitates better management of the disease in the TMJ. The aim of this review article is to highlight and update the prevalence, diagnosis, pathogenesis and general characteristics of TMJ Osteoarthritis.
\end{abstract}

Keywords: Degenerative joint disease, Temporomandibular joint, Osteoarthritis, Review, Epidemiology

\section{INTRODUCTION}

Osteoarthritis is characterized by chronic degeneration of the bony, cartilaginous and soft tissues in and around the joint and causes joint pain due to alteration in peripheral and central pain processing mechanisms. ${ }^{1}$ Stress bearing joints (knee, hips and spine) and fingers are often affected. $^{2}$ Temporomandibular disorders (TMD) consist of not only the internal derangement of Temporomandibular joint (TMJ) but also areas extrinsic to $\mathrm{TMJ}^{3}$ Osteoarthritis can also affect TMJ where it involves the cartilage, subchondral bone, and synovial membrane and results in TMJ remodelling and articular cartilage abrasion. Osteoarthritis can be localized to the TMJ in the beginning of this disease process. ${ }^{4}$ The aim of this review article is to highlight and update the prevalence, diagnosis, pathogenesis and general characteristics of TMJ Osteoarthritis.

\section{METHODS}

The data in this article are supported by a Medline search using the key words osteoarthritis, osteoarthrosis, and temporomandibular joint. These were augmented by references from these articles. No limits were applied to year of study; however I did exclude publications that were not in English. Relevant articles not found in the Medline were sought by a hand search review of reference books.

Data were extracted into a database developed for this systematic review. The data extracted included author, year of publication, evidence level of study, and recommendations made or disputed. Studies were subsequently categorized as levels 1 to 5 scientific evidence based on the US Agency for Health Care Research and Quality (Table 1). 
Table 1: Scientific levels of evidence and their descriptions (www.ahrq.gov).

\begin{tabular}{|c|c|}
\hline $\begin{array}{l}\text { Level of } \\
\text { evidence }\end{array}$ & Description \\
\hline 1 & $\begin{array}{l}\text { Randomized controlled trials (RCTs) with } \\
\text { adequate follow-up, Meta-analysis of } \\
\text { multiple RCTs }\end{array}$ \\
\hline 2 & $\begin{array}{l}\text { Nonrandomized, controlled prospective } \\
\text { trial, Prospective cohort studies }\end{array}$ \\
\hline 3 & $\begin{array}{l}\text { Well-designed observational studies such } \\
\text { as comparative studies, correlation study, } \\
\text { case control study. }\end{array}$ \\
\hline 4 & $\begin{array}{l}\text { Retrospective observational studies } \\
\text { without controls, Case-series }\end{array}$ \\
\hline 5 & $\begin{array}{l}\text { Expert opinion or committee } \\
\text { recommendations }\end{array}$ \\
\hline
\end{tabular}

\section{RESULTS}

\section{Epidemiology}

Approximately $15 \%$ of the world's population is suffering from osteoarthritis and perhaps 22-29\% of people in India suffer from osteoarthritis. ${ }^{5,6}$ Though there is no age bar it occurs with greater frequency as age advances. At 40 years of age, about $20 \%$ may have osteoarthritis. ${ }^{7}$ In the age group of 73-75 years, $70 \%$ of the people showed radiographic evidence of osteoarthritis. ${ }^{8}$ However, symptoms manifest in only $9.6 \%$ of men and $18 \%$ of women of $\geq 60$ years of age. The peak prevalence is reported in 5 th and 6 th decade and there occur reduction in the progression after 75 years. ${ }^{9}$ Epidemiologic findings of TMJ osteoarthritis are similar to generalized osteoarthritis. The clinical evidence of TMJ osteoarthritis occurs in $8-16 \%$ of population and involvement may be unilateral or bilateral. ${ }^{10}$ Females are affected more and it may be due to Estrogen Receptor alpha polymorphism and increased pain susceptibility. ${ }^{11}$

\section{Risk factors}

The causes of TMD and TMJ disorders include internal derangement, masticatory muscles disorders, chronic mandibular hyper and hypo-mobility and inflammatory diseases. ${ }^{3}$ Osteoarthritis has multiple risk factors' such as age, genetics, trauma, joint and muscle disorders, infection, generalized osteoarthritis, congenital and developmental abnormality and idiopathic degenerative process. Trauma includes past fractures, repetitive adverse loading, high-impact and torsional loads, external or overt jaw trauma and prolonged micro trauma. Joint and muscle disorders consist of joint instability, inadequate muscle strength/endurance, internal derangements, discectomy and ligament laxity. ${ }^{12}$

\section{Natural course and three phases}

TMD patients with myogenic pain usually have normal TMJ. The limitation of jaw movement is due to muscle pain and stiffness. Myogenic disorders include myofascial pain, fibrositis, muscle splinting (trismus), spasm and swelling (myositis), contracture, bruxism, hypertrophy and dyskinesia. ${ }^{3}$ The natural course of TMJ osteoarthritis is usually favorable and consists of periods of remission and cartilage regeneration. It is divided into three slow progressive phases. ${ }^{13,14}$ The disease process takes about 5.5 years from initiation to the final burnout phase. $^{14}$

1. Early phase (2.5-4 years): During evolution of the disease, patient complaints of clicking sounds and intermittent locking.

2. Intermediate phase (6 months to 1 year): It is associated with TMJ destruction and patient develops spontaneous joint pain at rest or with function, limitation in opening of mouth and grating sounds.

3. Late phase (burnout phase) (6 months): There is no degenerative activity, and TMJ eventually stabilizes with time. Therefore, if invasive procedures can be postponed with medical management, patients will ultimately benefit from it. There is no joint pain but some patient may have limitation of mouth opening and grating sounds.

\section{Clinical features}

The most common clinical features of TMJ osteoarthritis are pain, restriction in mouth opening, joint crepitus sounds and absence of joint warmth. Pain is generally dull aching and common during the initial phases and is due to the synovitis. ${ }^{13}$ Some patients have morning joint stiffness and increased sensitivity to cold and damp. The pain relieving factors include rest and NSAIDs. In later stages patient may develop facial skeletal remodelling. Chin deviation occurs toward the affected side. Occlusal discrepancies and unstable or fluctuating malocclusion are not uncommon. Occlusal changes include anterior open bite, reduced overbite and increased overjet. ${ }^{12}$ Internal derangements occur in about one-third of the patients. $^{8}$

\section{Investigation}

Rheumatoid factor titre if less than 1:40 and rules out rheumatoid arthritis. The elevation in Erythrocyte sedimentation rate $(\mathrm{ESR})$ and $\mathrm{C}$ reactive protein indicates an infectious/inflammatory lesion. ${ }^{2} \mathrm{OPG}$, the panoramic view is the imaging of choice for screening and assessing the overall status of maxillo-mandibular complex. It shows only gross disease (degenerative and ankylosis) and general TMJ configuration. ${ }^{3}$ OPG findings of TMJ osteoarthritis includes flattening of the superior surface of condyle, loss of joint space, bird-beaking and generalized 
sclerosis of the articular surfaces. CT scan is ideal for fine osseous and fibrous evaluation. ${ }^{3}$ TMJ tomograms are good for osseous condylar abnormalities. ${ }^{15}$ Both transpharyngeal and transcranial views are no longer used. One study found that for the radiologic diagnosis of TMJ osteoarthritis, reliability and marginal sensitivity was inadequate for panoramic view, average for MRI, and close to the threshold of excellent for CT. MRI is ideal for evaluating disk morphology and position and early degenerative bone changes. MRI was found reliable and excellent for disc displacements. Cone beam CT reproduces images in axial, coronal and sagittal planes of TMJ and offers a comprehensive view of its bony components. ${ }^{15}$ The most common morphological changes observed are flattening of anterior surface of the condyle; erosions and irregularities of joint surfaces, flattening of the articular surface of temporal eminence, subchondral cysts, osteophytes and idiopathic condyle resorption. ${ }^{16}$ Ultrasonography, which is economical, has shown promising results. ${ }^{17}$

\section{DISCUSSION}

Epidemiologic findings of TMJ osteoarthritis are similar to generalized osteoarthritis. The clinical evidence of TMJ osteoarthritis occurs in $8-16 \%$ of population and involvement may be unilateral or bilateral. ${ }^{10}$ TMD patients present with musculoskeletal symptoms such as diffuse facial pain with jaw movements, limitation of mandibular movement and masticatory muscles and TMJ tenderness. ${ }^{3}$ American Academy of Orofacial Pain classifies TMJ Osteoarthritis into primary and secondary. In primary TMJ osteoarthritis there is no local or systemic factor while secondary TMJ osteoarthritis is associated with a previous traumatic event or disease. ${ }^{4}$

Nocturnal or diurnal bruxism (grinding or clenching) is very common. It is more during physical or emotional stress. This strain on TMJ which is due to overuse or improper use must be treated as such. ${ }^{3}$ TMD and TMJ disorders occur due to the misalignment of one TMJ. TMD may be caused by malocclusion, abnormal bite, or faulty dentures. ${ }^{3}$ A sustained inflammatory process is the main constituent of pathogenesis of osteoarthritis. ${ }^{2,5}$ Early damage to the joint cartilage due to certain metabolic and mechanical factors triggers an immune response, a series of biomechanical changes in the joint tissues and release of cytokines and chemokines. There occurs activation of the complement system and release of cartilage degrading factors [matrix metalloproteinase (MMPs) and prostaglandin E (PGE)] that further damage the articular cartilage. These factors eventually lead to degradation and abrasion of joint cartilage and remodelling of the subchondral bone.,12

Patients with internal derangement of TMJ (disc displacement, osteoarthrosis, inflammation, and congenital, developmental, traumatic and neoplastic disorders) present with well localized pain. ${ }^{3}$ The findings of patient history and physical examination are integrated with preliminary radiographic evidence to make provisional diagnosis of TMJ osteoarthritis which should be confirmed through necessary imaging and laboratory studies for the successful management of these patients with TMJ osteoarthritis. In jaw (masticatory) claudication, which is a feature of giant cell arteritis, pain develops progressively with mastication. ${ }^{3}$ Treatment of TMJ osteoarthritis depends upon the stage of the disease, symptoms and risk factors and is directed at suppressing the inflammatory process, preserving function, preventing deformity and relieving pain. ${ }^{12}$ Early multimodal therapies have shown best results for the long term management. Nonsurgical treatment can successfully be used to treat these patients and consists of physical therapy, pulsed electrical stimulation, pharmacological, topical ointments, supplements, steroid injections, hyaluronic acid (HA) injections and acupuncture. ${ }^{18}$

\section{CONCLUSION}

Osteoarthritis of TMJ is not rare. The disease progresses slowly and passes through different phases with periods of remission and ultimately results in the burnout phase. Majority of patients shows radiographic evidence of TMJ osteoarthritis. The first line of treatment of TMJ osteoarthritis is conservative therapy due to the nonprogressive nature of the advanced stages. Diagnosis of different stages of TMJ osteoarthritis is important to provide contingent treatment. The most common clinical features of TMJ osteoarthritis are pain, restriction in mouth opening, joint crepitus sounds and absence of joint warmth. Pain is generally dull aching and common during the initial phases and is due to the synovitis. Advanced stage is effectively managed by conservative non-surgical techniques. Conservative modality of treatment is effective and causes least morbidity.

\section{Funding: No funding sources \\ Conflict of interest: None declared \\ Ethical approval: Not required}

\section{REFERENCES}

1. Poole AR. Osteoarthritis as a whole joint disease. HSS J. 2012;8(1):4-6.

2. Jacofsky, David J, Anderson, Meredith L, Wolff III, Luther H. Osteoarthritis Hospital Physician 2005;41(7):17-25

3. Bansal M. Diseases of Ear, Nose and Throat. Jaypee Brothers Medical Publishers (P) Ltd. New Delhi. 2013;121-2.

4. Lories RJ, Luyten FP. Osteoarthritis as a whole joint disease. The bone-cartilage unit in osteoarthritis. Nat Rev Rheumatol. 2011;7:43-9.

5. Kidd B. Mechanisms of pain in osteoarthritis. HSS J. 2012;8(1):26-8.

6. Chopra A, Patil J, Bilampelly V, Relwane J, TandleH S. Prevalence of rheumatic disease in rural 
population in Western India: a WHO-ILARCOPCORD study. $\mathrm{J}$ Assoc Physicians India. 2001;49:240-6.

7. Lawrence RC, Helmick CG, Arnett FC, Deyo RA, Felson DT, Giannini EH, et al. Estimates of the prevalence of arthritis and selected musculoskeletal disorders in the United States. Arthritis Rheum. 1998;41(5):778-99.

8. Bagge E, Bjelle A, Edén S, Svanborg A. Osteoarthritis in the elderly: clinical and radiological findings in 79 and 85 year olds. Ann Rheum Dis. 1991;50(8):535-9.

9. Bagge E, Bjelle A, Edén S, Svanborg A. Osteoarthritis in the elderly: clinical and radiological findings in 79 and 85 year olds. Ann Rheum Dis. 1991;50(8):535-9.

10. Mejersjo C. Therapeutic and prognostic considerations in TMJ osteoarthrosis: a literature review and a long-term study in 11 subjects. Cranio. 1987;5(1):69-78.

11. Kang SC, Lee DG, Choi JH, Kim ST, Kim YK, Ahn HJ. Association between estrogen receptor polymorphism and pain susceptibility in female temporomandibular joint osteoarthritis patients. Int $\mathbf{J}$ Oral Maxillofac Surg. 2007;36(5):391-4.

12. Tanaka E, Detamore MS, Mercuri LG. Degenerative disorders of the temporomandibular joint: etiology, diagnosis, and treatment. J Dent Res. 2008;87(4):296-307.

13. Buckwalter JA. The role of mechanical forces in the initiation and progression of osteoarthritis. HSS J. 2012;8(1):37-8.

14. Stegenga B, de Bont LG, Boering G, van Willigen JD. Tissue responses to degenerative changes in the temporomandibular joint: a review. J Oral Maxillofac Surg. 1991;49(10):1079-88.

15. Meng JH, Zhang WL, Liu DG, Zhao YP, Ma XC. Diagnostic evaluation of the temporomandibular joint osteoarthritis using cone beam computed tomography compared with conventional radiographic technology. Beijing Da XueXueBao. 2007;39(1):26-9.

16. Dimitroulis G. The prevalence of osteoarthrosis in cases of advanced internal derangement of the temporomandibular joint: a clinical, surgical and histological study. Int $\mathbf{J}$ Oral Maxillofac Surg. 2005;34(4):345-9.

17. Landes C, Walendzik H, Klein C. Sonography of the temporomandibular joint from 60 examinations and comparison with MRI and axiography. SonographyJ Craniomaxillofac Surg. 2000;28(6):352-61.

18. de Leeuw R, Boering G, Stegenga B, de Bont LG. Symptoms of temporomandibular joint osteoarthrosis and internal derangement 30 years after non-surgical treatment. Cranio. 1995;13(2):81-8.

Cite this article as: Bansal M. Prevalence and diagnostic features of osteoarthrosis of the temporomandibular joint: a review. Int J Res Orthop 2016;2:1-4. 